\section{Science and human rights}

SIR - We should like to amplify your News story (Nature 368, 680; 1994) about a session of the Committee on International Freedom of Scientists (CIFS) at the annual meeting of the American Physical Society. Your report detailed one case but other important issues were also discussed at the session.

For example, the Chinese physicists Wang Juntao and Liu Gang were among those imprisoned after peacefully participating in the demonstration in Tiananmen Square in 1989 and have been held under severe conditions. Wang's wife, Hou Xiaotian, spoke at the meeting of his critical medical condition. CIFS had joined other groups in petitioning for Wang's early release to receive medical treatment for hepatitis B. Six days after the CIFS session (and just before President Bill Clinton's decision to renew China's 'Most Favored Nation' status), Wang was 'medically paroled' and is now being treated in the United States. Liu Gang remains in Linguan Prison No. 2 under harsh conditions.

As a result of protests by CIFS and other scientific and human rights organizations, charges were dropped against Vil Mirzayanov, the Russian whistleblower who revealed continued secret Russian manufacture of binary chemical weapons in spite of a treaty prohibiting such manufacture. In Uzbekistan, mathematicians and physicist members of Birlik, a prodemocracy group, were arrested and imprisoned for peaceful expressions of opinion. Abdummammob Pulatov provided the meeting with details of the latest cases of repressed scientists.

CIFS has also protested at the US government's infringement of the right of scientists to travel freely to and from Cuba to exchange scientific information. A statute dating back to the First World Warthe Trading with the Enemy Act - effectively prevents Americans from attending conferences in Cuba, even those sponsored by the International Union of Pure and Applied Physics and the International Council of Scientific Unions. Similarly, Cuban scientists are not normally admitted to the United States; as a result, an international conference was shifted to Vienna last year.

On the complaint of a former East German physicist that your correspondent referred to, the physicist concerned admitted being an inoffizial Mitarbeiter (unofficial collaborator) of the Stasi (the East German secret police), but claimed he had not received fair treatment at the hearing that resulted in his dismissal. Over the past two years, CIFS has been in touch with his colleagues and academic superiors and officials of the German Physical Society to determine whether he received a fair hearing. The case is still in progress. Another case concerns Mohammed AlMass'ari, a Saudi Arabian professor of physics at Riyadh University, who was arrested, imprisoned and held incommunicado while his office and home effects were confiscated. Many of his colleagues were also arrested. $\mathrm{He}$ is a member of the Committee for the Defence of Legitimate Rights.

In these and other cases, CIFS interventions are intended to express concern for the right of individual physicists and other scientists to pursue their scientific activities in accordance with internationally recognized principles.

\section{Joseph BIrman}

Fang Lizhi

Herman Winick

Eugene Chudnovsky

Yuri Orlov

Committee on the International

Freedom of Scientists 1994,

American Physical Society,

One Physics Ellipse,

College Park, Maryland 20740-3844, USA

\section{AIDS research}

SIR - Bernard N. Fields makes a number of cogent comments in his proposal for redirection of AIDS research (Nature 369, 95-96; 1994). But to suggest that "it is no longer reasonable to invest major resources in the search for drugs and vaccines" is a highly provocative point of view, one whose implementation might affect the lives of hundreds of thousands of HIV-infected people over the next 10 years.

This discourse is not solely an academic debate about what gets studied: it is at least equally about who gets federal grant money. The two points are inseparable, and the latter cannot help but affect beliefs about research priorities. Many basic laboratory scientists not directly associated with AIDS work have complained bitterly about the perceived shift in funding to AIDS and other diseasespecific research. It is essential that widespread public review should precede any changes in priorities as proposed by Fields. Most critically, we must hear from those scientists who have spent much of the past decade directly working on this problem. In the absence of a clear, specific plan and an open debate, it will be all too easy to see any change as an effort to shift grant support from one group of scientists to another.

Letters submitted for Correspondence should be typed, double-spaced, on one side of the paper only.
The best way to accomplish productive change would be to convene a formal (and long overdue) assessment process of AIDS research, one which includes but is independent from the US National Institutes of Health as well as the interests of any individual scientific specialty. Fields should indeed be heard, but so should the views of many other scientists who have worked for the past decade on various aspects of AIDS research.

Martin Delaney

Project Inform,

98 Cazneau,

Sausalito, California 94965, USA

SIR - While it is hard to disagree with Fields' call for funding of basic research in the fight against AIDS, his proposal may result in throwing out the baby with the bath water. Leaving aside the difficult question of what distinguishes 'basic' from 'applied' HIV research, bench scientists studying the interactions of HIV and the immune system have found it invaluable to have access to human samples from experimental HIV vaccine volunteers. These specimens have facilitated investigations of the fine specificity of cytotoxic $T$ cell responses, antigen and virus induced production of Th1 and Th2 cytokines, proliferative responses of cells to various strains of HIV envelope following immunization and the generation of antibody responses (including the phenomena of cross-reactivity, cross-neutralization and "original antigenic sin").

Precise knowledge of the timing of exposure, genotype and phenotype of isolated gene products, and baseline immune status of vaccine volunteers, is particularly useful in designing controlled experiments. This knowledge is a luxury not usually afforded scientists when studying infected individuals (even prospectively). In short, if one were designing a national programme for the basic study of immune system HIV interactions and did not already have an experimental HIV vaccine network in place, it would have to be created.

It should also be noted that private industry has probably invested at least as much as the US government in HIV vaccine development which, like most vaccine development, is a partnership between industry, government and academic institutions. The concerns of private-sector partners should at least be considered when policy is formulated to reconfigure or eliminate government programmes that depend on private sector participation.

\section{David H. Scwhartz}

Department of Immunology and

Infectious Diseases,

Johns Hopkins University,

624 N. Broadway,

Baltimore, Maryland 21205-1901, USA 